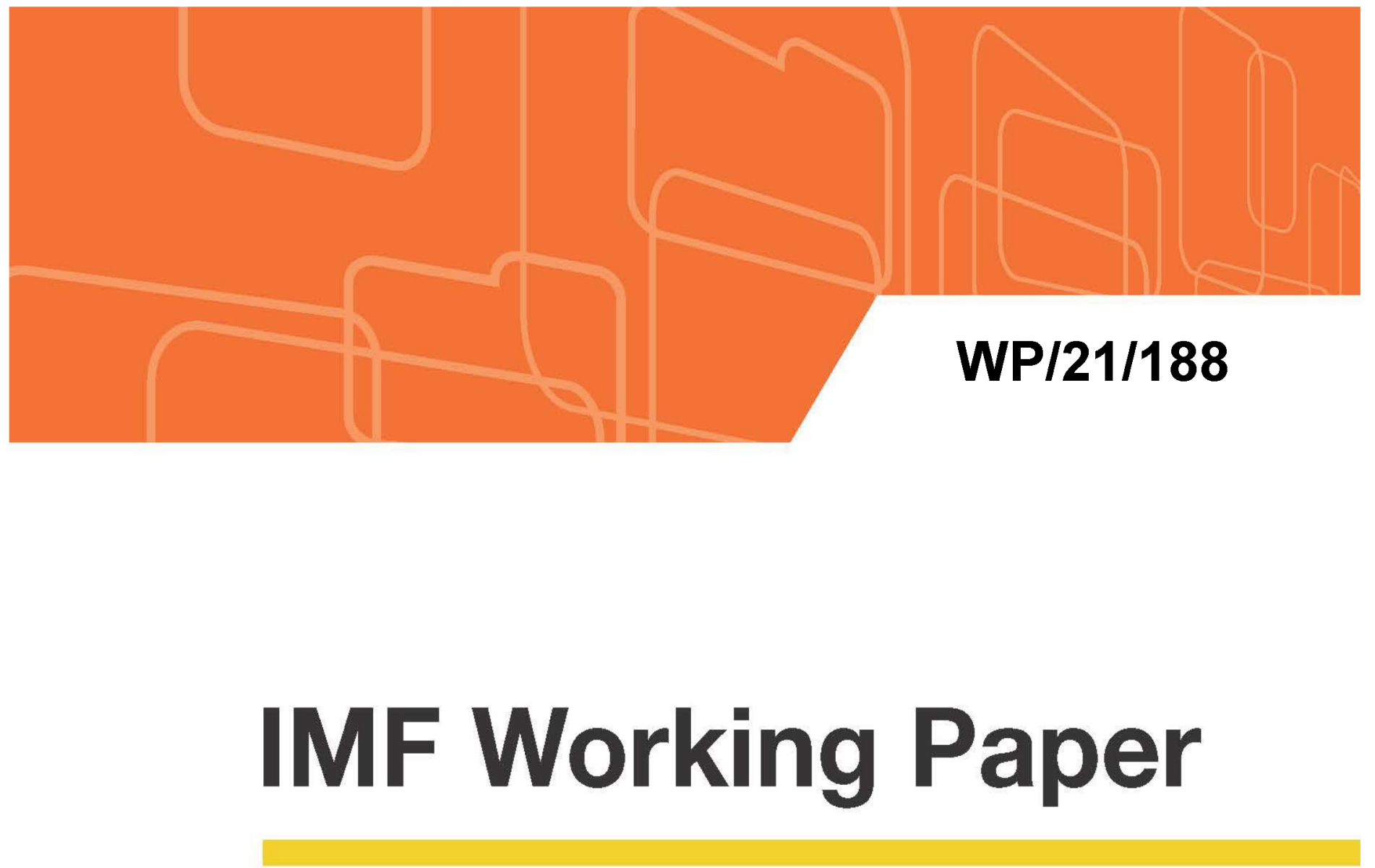

\title{
Reforming the Greek Pension System
}

by Alvar Kangur, Niki Kalavrezou, Daehaeng Kim

IMF Working Papers describe research in progress by the author(s) and are published to elicit comments and to encourage debate. The views expressed in IMF Working Papers are those of the author(s) and do not necessarily represent the views of the IMF, its Executive Board, or IMF management. 


\title{
IMF Working Paper
}

European Department

\section{Reforming the Greek Pension System}

\section{Prepared by Alvar Kangur, Niki Kalavrezou, Daehaeng Kim}

Authorized for distribution by Dennis Botman

July 2021

\section{IMF Working Papers describe research in progress by the author(s) and are published to elicit comments and to encourage debate. The views expressed in IMF Working Papers are} those of the author(s) and do not necessarily represent the views of the IMF, its Executive Board, or IMF management.

\begin{abstract}
The Greek pension system has been costly, complex, and distortive, which has contributed to Greece's fiscal problems and discouraged labor force participation. Several attempts to reform the system faltered due to lack of implementation, pushback by vested interests, and court rulings leading to reversals. A series of reforms introduced throughout 2015-17 unified benefit and contribution rules, removed several distortions and reduced fragmentation and costs. If fully implemented throughout the long-term, these reforms can go a long way towards enhancing the pension system affordability. However, reforms faced setbacks and fell short of creating stronger incentives to build long contribution histories, to deliver sustainable growth by improving the fiscal policy mix, and to ensure fairness and equitable burden sharing across generations and interest groups. Policy priorities should aim towards fully implementing the 2015-17 reforms and complementing them with additional reforms to address these remaining objectives.
\end{abstract}

JEL Classification Numbers: E62, H55, J11, J26.

Keywords: pension reform, labor market incentives, fiscal consolidation.

Author's E-Mail Address: AKangur@imf.org; NKalavrezou@,imf.org; DKim2@,imf.org 


\section{CONTENTS}

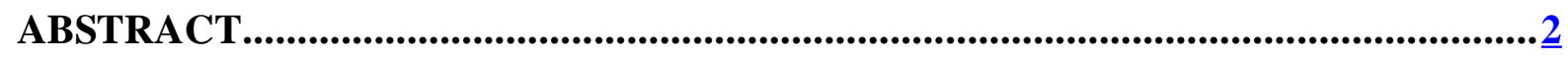

I. BACKGROUND: EARLY PENSION REFORMS AND OUTCOMES......................... 4

II. CHARACTERISTICS OF THE PENSION SYSTEM PRIOR TO THE 2015-16

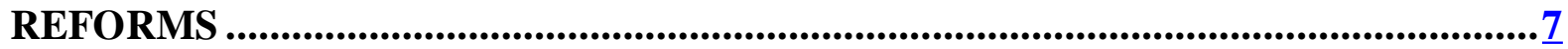

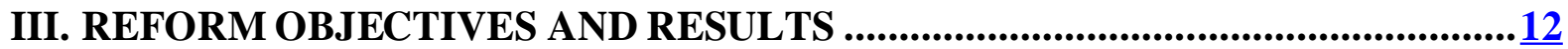

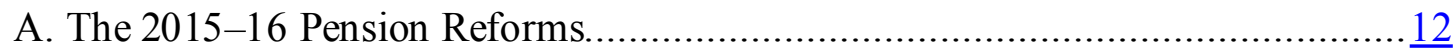

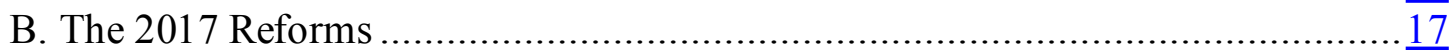

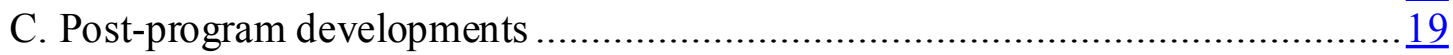

IV. CONCLUSIONS AND POLICY RECOMMENDATIONS........................................22

\section{BOXES}

1. The Greek Pension System Prior to 2015-16 Reforms ……....................................... $\underline{8}$

2. Long-Term Pension Spending Projections ...........................................................

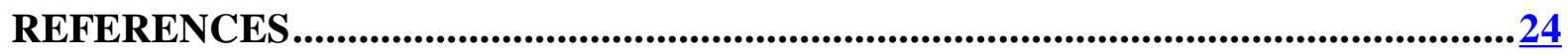




\section{REFORMING THE GREEK PENSION SYSTEM}

\section{BACKGRound: EARly Pension Reforms AND OUtComes}

1. Excessive pension spending was one of the main drivers of Greece's poor fiscal performance prior to the crisis. During 2000-10, Greece's pension spending increased from close to 11 percent of GDP (below the euro-area average of 12 percent) to almost 15 percent (the second highest in the euro area, after Italy). This represents the largest increase in relative terms among peers, and was due to a rapid increase in nominal pensions on account of high wage and price growth, combined with generous benefits (pensions were linked to the best five of the last 10 years of one's wage history) and numerous options for early retirement along with low actuarial reductions when retiring before statutory retirement age (providing pathways to retirement extensively used at the time of crisis). As a result, the system's deficitthe difference between pension benefits and contributions - reached an estimated 7.3 percent of GDP by 2010, being the largest contributor to the overall general government deficit (of close to 11 percent). ${ }^{1}$ Moreover, pension projections pointed to a significant solvency problem, prompting the OECD to describe the Greek pension system as "a fiscal time bomb," as pension spending was expected to double by 2050 , driven by rapid population aging and a doubling of the

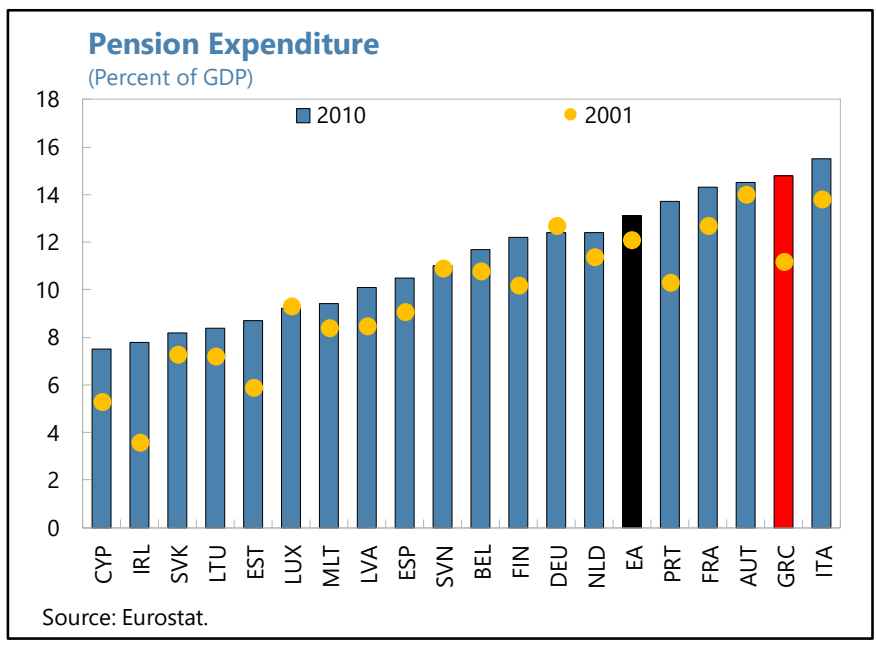
old-age dependency ratio (OECD, 2007; EC 2009).

2. A comprehensive reform was undertaken in $\mathbf{2 0 1 0}$ aiming to address the long-term sustainability of the pension system. The reform aimed to contain future pension spending by tightening eligibility conditions and introducing a less costly benefit rule for new retirees, among others. Specifically, it set the early and statutory retirement age at $60 / 65$ for all insured, while increasing the required years of contributing (from 35 to 40 ). It also tightened early retirement rules by introducing a comprehensive penalty for early retirement and streamlining the list of hazardous professions entitled to early retirement options. The benefit formula was redesigned by introducing a basic pension component ( $€ 360$ per month) in addition to an earnings-related pension with "average" accrual rates - annual proportion of pensionable earnings transformed into a pension benefit - ranging from 0.8 to 1.5 percent of earnings, compared to $2-3$ percent before the reform, and introduced uniformly for all main pension funds (except the farmers' fund OGA). However, while the reform linked pensionable earnings to the lifetime earning history (rather than the best five of the last ten years), the introduction of the non-contributory basic pension flattened the benefit schedule and weakened contribution-benefit links. Moreover, the reform was undermined by extensive grandfathering of previous early retirement options, which led to a massive wave of early retirements to take advantage of the previous more generous rules.

\footnotetext{
${ }^{1}$ This figure is likely an underestimate, as it excludes lump-sum pensions.
} 
Finally, its key element — the unified benefit rule — set to become effective as of 2015 was never applied.

\section{Further reforms during 2011-13 sought to contain the medium-term costs of the}

pension system. The reforms introduced a zero-deficit rule for auxiliary pension funds aiming to ensure the elimination of their annual deficits, increased the early and statutory retirement ages by a further two years (to 62 and 67, respectively), and froze the indexation of pensions (previously linked to GDP growth and inflation) until 2016. In addition, the reforms reduced the benefits of current retirees, including by initially reducing and subsequently eliminating the $13^{\text {th }}$ and $14^{\text {th }}$ pension payments ("holiday bonuses") and introducing a series of progressive cuts of main and supplementary pensions above certain limits. ${ }^{2}$ However, these reforms also suffered from serious setbacks. The zero-deficit rule was not implemented, leading to continued deficits that had to be financed from the general budget or drawing down assets. The increase in the retirement age lacked effectiveness due to extensive grandfathering. And the 2012-13 pension cuts (expected to yield 2 $1 / 4$ percent of GDP in gross fiscal savings) were ruled unconstitutional by a supreme court (Council of State, CoS) decision in $2015 .^{3}$

4. Despite the successive reforms, pension spending continued to rise. Pension spending increased from 14.8 to 17.7 percent of GDP during 2010-2015. Although the average pension (calculated as the ratio of nominal pension spending to the number of retirees) declined by about 8 percent during this five-year period, this was not sufficient to offset the decline in GDP (by around 25 percent), leading to an increase in pension spending relative to output. ${ }^{4}$ While part of the increase could be considered cyclical, as GDP is expected to recover over time, pension spending is also likely to grow along wage growth and inflation. Taking into account cyclical effects (i.e. dividing

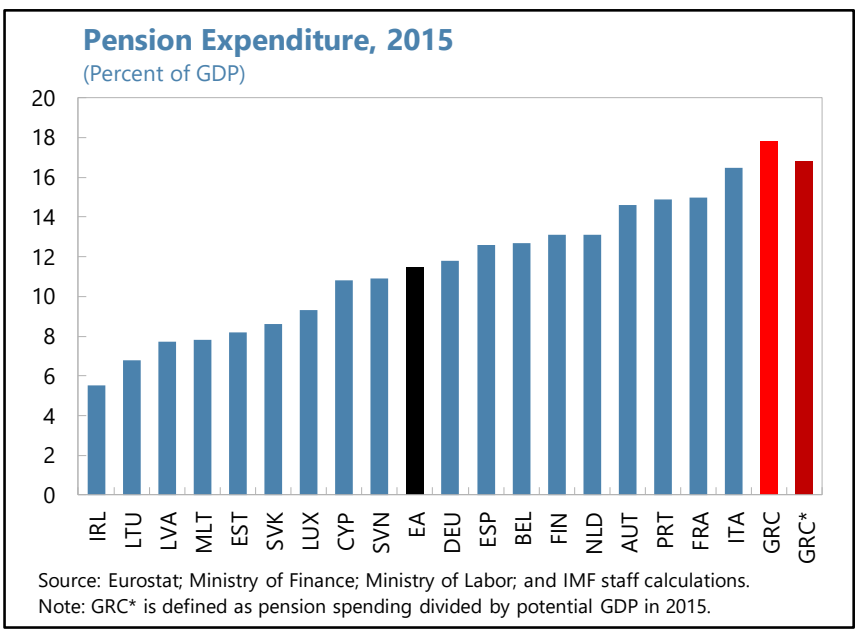
pension spending in 2015 by potential output), the increase since 2010 is smaller, at 2.0 percent of GDP, although Greece's pension spending still remains the highest in the euro-zone. Fouejieu and others (2021) show that providing high returns on contributions in terms of pension benefits was a structural feature of the Greek pension system also before the Global Financial Crisis on a broadly comparable scale to the crisis time. Moreover, the evolution of pension spending over

\footnotetext{
2 These targeted mainly main monthly pensions above $€ 1,300$, and above $€ 1,000$ of retirees younger than 55 , as well as supplementary pensions at various ranges.

${ }^{3}$ The CoS did not find sufficient evidence of exceptional circumstances to support the 2012 reform s and concluded that a scientific study should have examined if the measures were "appropriate and necessary" to address the problem of sustainabili ty of the pension system, taking into account the effect of all measures (e.g. tax reforms, cost of goods an d services etc.) on retiree's living standards. The CoS also found that pension cuts applied only to certain categories of pensioners and that alternatives to pension cuts were not sufficiently explored, thus violating the principle of equal participation in public charges and the principle of social solidarity.

${ }^{4}$ Relative to a no-reform scenario, the reduction in the average pension per retiree is estimated at around 24 percent, as pensions per retiree were projected to increase by 16 percent on the basis of the pre-reform parameters.
} 
this period stands in sharp contrast to other spending categories - in particular investment and discretionary spending - which were compressed significantly relative to GDP to help reduce the fiscal deficit (along with tax rate increases).

\section{While social contribution rates are above the euro-area average, contribution} revenues have been low compared to peers. Pension contribution rates for both employers and employees, including main and supplementary pensions, stood at 26 percent in the run-up to May 2016 reforms, above the euro-area average of 21 percent. Together with high income taxes, this adds to relatively high marginal and average tax wedges in Greece. ${ }^{5}$ Nonetheless, pension contribution revenues have been relatively low by international comparison $\left(6 \frac{1}{2}\right.$ percent of GDP compared to a euro area average of about 8 percent in 2015). This is an indication that the Greek social security, similarly to the tax system, suffers from high rates levied on narrow bases, eroded by low payment and collection efficiency. ${ }^{6,7}$ At the same time, the prolonged recession has taken a significant toll on individuals' incomes and their ability to support the increasing tax and social security contribution burden, given the declining employment (by 19 percent since 2009), the high unemployment rate (25 percent at end-2015) and large wage reductions (more than 20 percent during 2010-15).
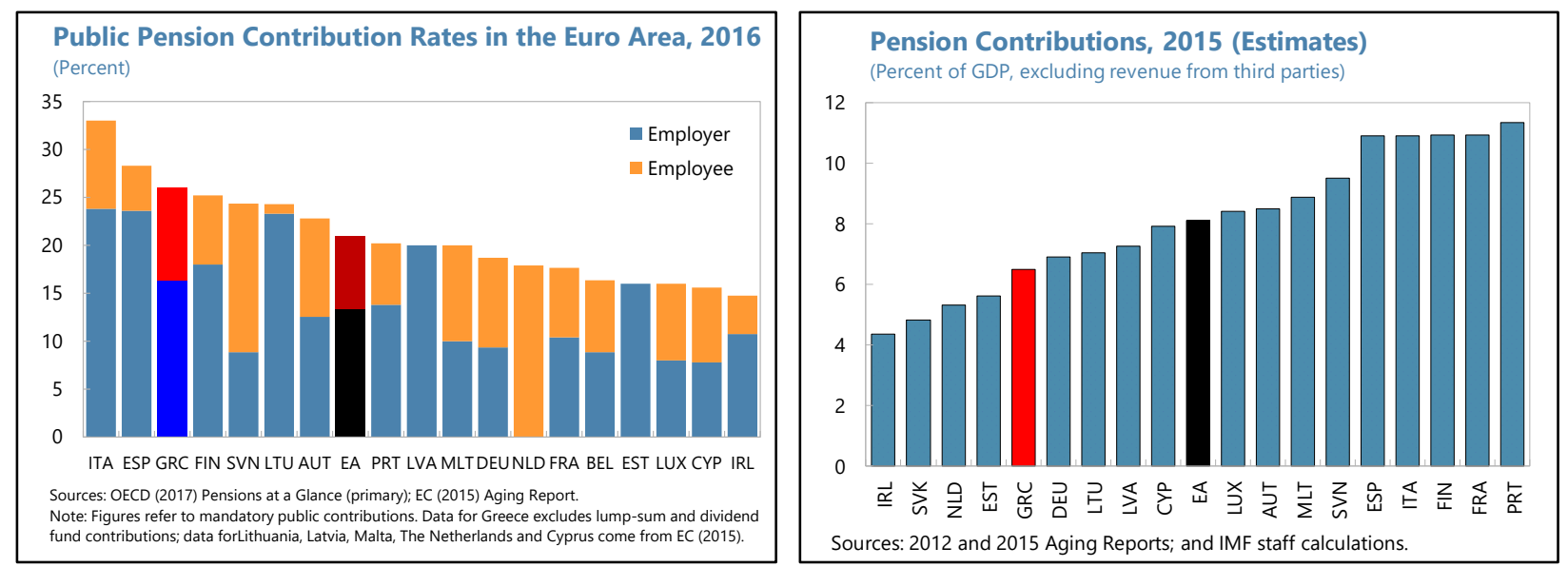

\section{With high pension spending and low pension contribution revenues, substantial state transfers have been needed to finance the large deficit of the pension system. Transfers}

\footnotetext{
${ }^{5}$ At 38.3 percent, the average tax wedge in Greece in 2016 for a one-earner married couple with two children and average earnings is much higher compared to 26.6 percent in the OECD or 31 percent in the euro area. In addition to pensions this reflects also high non-pension social security contributions. These relative magnitudes are similar for a two-earner family. While a single person with average earnings in Greece benefits from the exceptionally generous tax credit, a single person with a higher income is subject to steeply increasing marginal income tax rates. According to the OECD a single person receiving 67 percent above the average earnings faces a 56 percent marginal tax wedge, compared to 47 percent in the OECD and 53 percent in the euro area.

${ }^{6}$ Greece has one of the highest shares of the informal economy, incidence of tax evasion, and hours per week spent on undeclared work in the OECD (Andrews and others, 2011). According to the Ministry of Labor (Artemis reports, 2014), about 9 percent of audited employees and 18 percent of audited companies have not been formally declared and thus were not insured in late 2014.

${ }^{7}$ Collection rates have been only about 30-50 percent in the farmers' fund, 55 percent in the fund for s elf-employed, and about 80 percent in the fund for doctors, lawyers and engineers. As a result, large contribution arrears have accumulated across funds, especially among the self-employed where arrears are 4.5 times the annual revenue collected. See Selected Issues Paper (2017) "Addressing the Burden of Tax and Social Security Debt."
} 
to the pension system have risen from 7.3 percent of GDP (excluding lump-sum funds) in 2010 to more than $10 \frac{1}{2}$ percent of GDP by end $-2016 .{ }^{8}$ All main funds experienced large deficits, as in most cases contributions cover less than half of benefit spending, especially in funds in the energy and communication sectors, the navy and public administration and the funds for journalists, and doctors, engineers, and lawyers (ETAA), whose insured enjoy relatively high benefits. At the same time contributions in general are low as a result of, among other reasons, weak incentives to contribute, non-compliance and under-declaration of income. The state has been mandated to cover all these deficits, along with subsidizing the

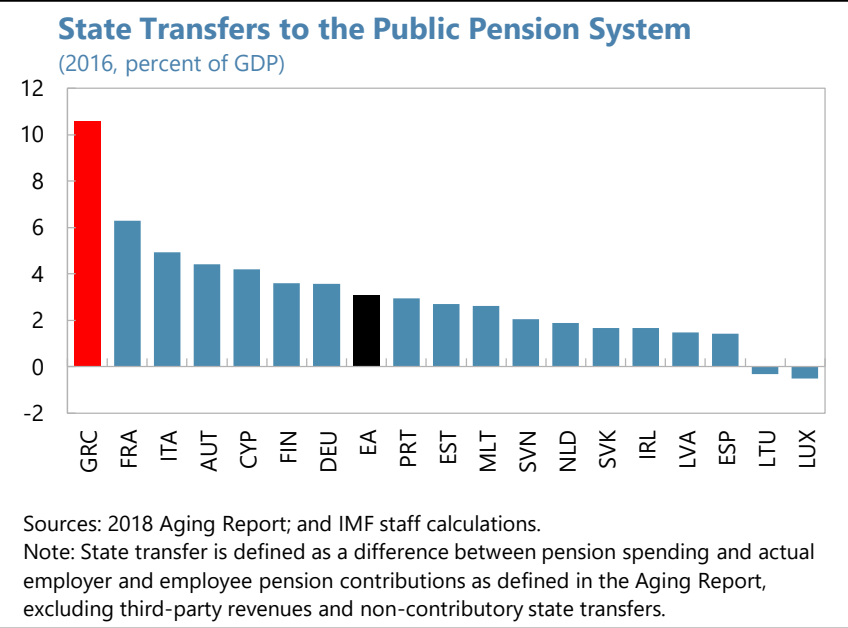
farmers' fund (OGA), since insured pay only the employees' contribution of 7 percent (less than 10 percent of benefits).

\section{Characteristics of the Pension System Prior to the 2015-16 Reforms}

\section{Despite the reforms, the pension system remained highly fragmented (Box 1). By} end-2014, the mandatory main pension system was differentiated into seven occupational funds. As the unified benefit rule of the 2010 reform that was set to take effect in 2015 was never applied, the funds retained their own rules. While most supplementary or auxiliary pension funds were merged under a single umbrella fund after the 2012 reform, they retained different degrees of autonomy and their own benefit formulas. In addition, several lump-sum and dividend funds provided additional benefits mostly for civil servants but also some professional groups. As a result, close to half of pensioners received one pension, 35 percent two, and 15 percent three or more pensions from the various funds. The pension provision consisted of multiple benefit layers, where basic, contributory, and minimum pensions in the main funds were topped up by auxiliary, lump-sum, dividend and/or targeted pensions (e.g. the EKAS benefit). Such degree of fragmentation contributed to intragenerational unfairness as different interest groups were subject to different rules and exemptions. Further, the introduction of a basic pension, various minimum and targeted pensions, as well as a series of past progressive cuts had considerably flattened the pension system and weakened its contribution-benefit links.

\footnotetext{
${ }^{8}$ To capture actuarial contribution-benefit links, consistent with the EC (2012) Ageing Report and definitions of employer and employee contributions in the subsequent Ageing Reports, the calculations exclude revenues from third-parties, government grants, income from property as well as any legislated state transfers not in the nature of actual co ntributions. Retroactive collections from amnesties (reaching ca $1 \frac{1}{2}$ percent of GDP per year on average in Greece) are also excluded to facilitate crosscountry comparability with actuarial studies along with one-off bonuses or 'social dividends' that in 2016 amounted to 0.4 percent of GDP. In preceding years, the state transfer to Greece exceeded 11 percent of GDP since 2016 includes a partial impact of the 2015-16 pension reforms (see below).
} 
Box 1. The Greek Pension System Prior to the 2015-16 Reforms

Prior to the 2016 reform, the Greek pension system was fragmented across occupations, types of pensions, and benefit rules. It provided main, a uxiliary, lump-sum, dividend, targeted, and social pensions as well as other contributory welfare benefits financed through a pay-as-you-go principle. The system was financed by state transfers, and in some cases by third-party charges benefitting special groups (e.g. journalists). The benefits were provided by a number of segmented funds with their own rules:

- $\quad$ The main pension providers comprised eight funds: IKA (sa laried workers, including a lso sub-funds covering Banks, TAP-DEH which is a Public electricity company, and others), PS (civil servants), OAEE (self-employed), OGA (a gricultural sector), ETAA (la wyers, doctors, and engineers), ETAP-MME (journalists), NAT (seamen), and a fund for Bank of Greece employees.

- Auxiliary (supplementary) pension funds, which in 2012 were merged into a single entity (ETEA) and in 2014 were transformed into a Notional Defined Contribution (NDC) system, pro-rated over defined benefit (DB) rules for pre-2014 contribution periods. The NDC included a sustainability factor that under a full pay-as-you-go principle required maintaining a zero deficit every year; however, the zero-deficit rule was not implemented.

Greece's pension benefits consisted of the foll owing components:

- Basic pension: introduced with the 2010 law as part of the main pension formula at a fixed level of $€ 360$ per month a vailable to all who were eligible to a pension.

- Contributory pension: the earnings-related component of main pensions calculated through a defined benefit (DB) formula. The a ccrual ra tes - annual share of pensionable ea rnings transformed into a pension benefit - varied widely across funds between 2 and 3 percent prior to the 2010 reforms, and between 0.8 and 1.5 percent, depending on years of insurance, a fter the reform.

- Guaranteed contributorypension (minimum pension): a pension benefit floor a pplied to the main (sum of basic and contributory) pensions. In the main pension fund IKA this floor wa s $€ 487-€ 600$ depending on family size. Supplementary pensions, lump-sum pensions and a solidarity grant were provided in a ddition to the gua ranteed contributory pension.

- Auxiliary or supplementary pensions: followed their own DB rules often subject to separateminimum pension limits with an eligibility linked to the main pension provision.

- Lump-sum and dividend pensions provided additional la yers of contributory benefits mostly to civil servants and selected categories of professionals / self-employed.

- EKASpension supplement: a means-tested solidarity grant provided to those who already qualified for an insurance pension up to a ceiling of $€ 850$ per month and pension income of $€ 767$ permonth, in monthly payments ranging from $€ 30$ to $€ 230$. The guaranteed contributory pension topped up with EKAS thus exceeded the minimum wage of $€ 684$.

- Social pension: a means-tested welfare benefit of $€ 360$ per month provided to elderly at 67 years of a ge who had not fulfilled the eligibility conditions for a social insurancepension. In 2017, the number of beneficiaries was about 26,000 , with a n a nnual cost of $€ 112$ million.

- Other pension benefits provided by the social security funds included summer camps, temporary accommodations to seamen etc. 


\section{Moreover, nominal pensions in Greece remained relatively generous by}

international standards, despite lower productivity. Despite reductions in pensions due to the reforms, the average old-age pension in Greece at end-2015 (the ratio of total monthly pension spending to the total number of retirees) was estimated at $€ 978$ (IDIKA, 2015) similar to the euro-area average, once it is adjusted for purchasing power parity (PPP). ${ }^{9}$ However, in Greece, pensions are granted at younger ages and based on shorter contribution periods, and productivity has lagged that of peer countries. For example, while pension benefits in Greece in 2014-15 (based on comparable PPP data) were almost identical to those in Germany, in Greece average wages and productivity were less than half of those in Germany (about half of euro area average) and workers in Greece retired on average 5 years earlier (text table). Furthermore, Fouejieu and others (2021) show that, on average, cohorts in Greece who retired around this time received lifetime benefits that in present value terms exceeded lifetime contributions

\begin{tabular}{|c|c|c|}
\hline \multicolumn{3}{|c|}{$\begin{array}{l}\text { Comparison of Greek and German Pension Systems } \\
\text { (Monthly amounts in Euros, unless stated otherwise) }\end{array}$} \\
\hline & Germany & Greece \\
\hline Standard Pension ("Eckpension") in 2014 & 1,287 & 1,152 \\
\hline Average pension (comparable data) in 2015 & 1,285 & 971 \\
\hline Average pension (comparable in PPS terms) in 2015 & 1,282 & 1,200 \\
\hline GDP per capita (2015) & 3,108 & 1,358 \\
\hline Average wage (2015) & 3,131 & 1,429 \\
\hline Ratio of standard per & $41 \%$ & $81 \%$ \\
\hline Ratio of average pension to average wage & $41 \%$ & $68 \%$ \\
\hline Minimum pension & $\mathrm{N} / \mathrm{A}$ & $>486+$ EKAS \\
\hline Effective retirement age (new old age pension) & 64 & 59 \\
\hline Average contributory period (new pensions, 2010) & 36.3 & 29.3 \\
\hline \multicolumn{3}{|c|}{$\begin{array}{l}\text { Sources: Eurostat, OECD, Social Security Administration, Bundesversicherungsamt (2014), } \\
\text { IDIKA, EC } 2012 \text { and } 2015 \text { Aging Reports, and staff calculations. }\end{array}$} \\
\hline \multicolumn{3}{|c|}{$\begin{array}{l}\text { Note: the Standard pension is calculated for an average wage earner with } 45 \text { years of } \\
\text { insurance retiring at } 65 \text { years of age. It provides a useful benchmark to compare pension } \\
\text { benefits without differences in actual retirement ages and contribution years. }\end{array}$} \\
\hline
\end{tabular}
by more than four-fold. The pension system thus remained far from being sustainable and actuarially fair.

\section{The generosity of pensions is also reflected in the replacement rate, which has} remained high in Greece relative to peers. The gross replacement rate (the ratio of the average pension of new retirees to the average wage at retirement) was about 81 percent at end-2013, the highest in the euro-area, and almost 30 percentage points higher than the euro-area average. This illustrates the relative generosity of pension benefits relative to what retirees earned prior to retirement, suggesting that strong incentives to retire remained even after the 2010-12 reforms. Another metric is the economic benefit rate (pension spending per individuals aged 65 and older relative to GDP per working age population), which was 54 percent compared to a euro area average of 43 percent. This indicator suggests that benefits per retiree in

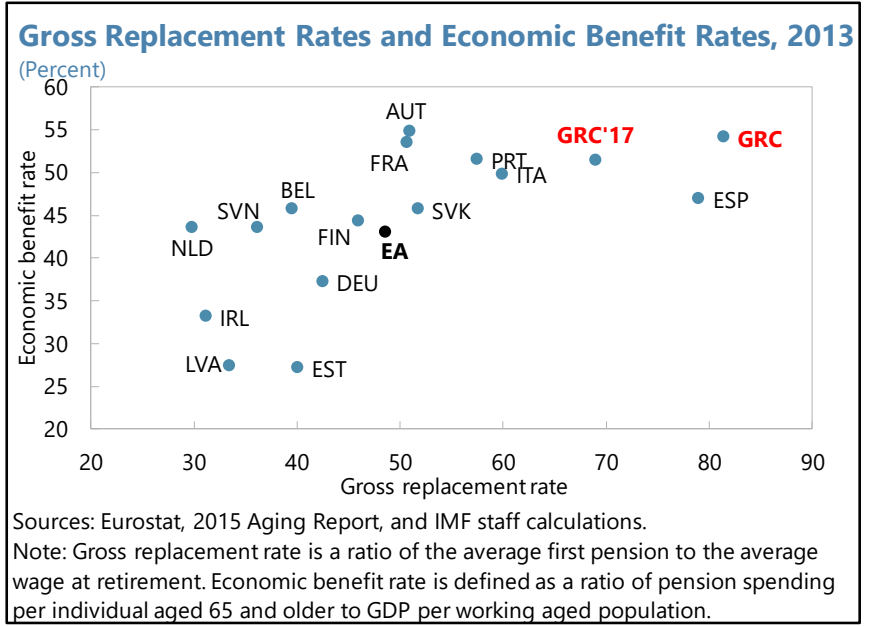

wage at retirement. Economic benefit rate is defined as a ratio of pension 65 and older to GDP per working aged population.
per indival aged

\footnotetext{
${ }^{9}$ The analysis here and throughout this paper refers only to public pension provision. Private or occupational pensions are excluded, as they are generally fully funded, not mandatory, and do not replace the coverage of public pensions. Thus, private pensions do not burden public finances directly, and private contributions do not constitute a revenue for the general government.
} 
Greece remained relatively high compared to the economic resources available to the workforce supporting the retirees.

\section{A corollary of generous pensions relative to wages is that the poverty rate among} pensioners has declined, while that for the working-age individuals has increased, pointing to an unequal distribution of the adjustment burden. Despite the income losses among retirees noted above, pensioners in Greece carry the lowest risk of poverty within the Greek population. In particular, the poverty rate for retirees has declined by more than 9 percentage points since 2010 to 9.7 percent at end-2016, below the euro area average (of 13.0 percent), and well below 18 percent in Germany. If one accounts for the very high share of home ownership of the elderly population ( 84 percent in Greece compared to 53 percent in Germany), the poverty of pensioners would be even smaller (OECD, 2013). In contrast, the brunt of the adjustment has been borne by the working-age population, whose poverty rate has increased to 23.5 percent at end2015, well above the euro-area average of 18.2 percent.

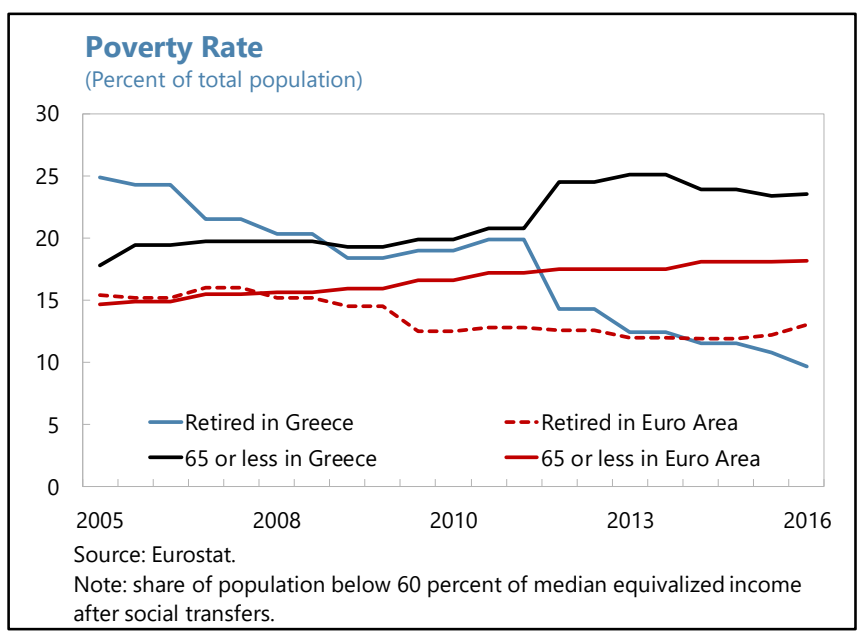

11. In addition, minimum pensions remained generous by international standards, curtailing incentives to work and contribute. Targeted and minimum pensions aim at guaranteeing a minimum standard of living after retirement but can be costly and are also some of the most important determinants of labor market incentives. In Greece, the minimum pension amounted to $€ 5,844-€ 8,400$ annually, exceeding the standard poverty threshold of $€ 4,500$ (EUSILC, 2016), and being among the highest in the euro area. ${ }^{10}$ In addition, Greek pensioners were eligible to receive a means-tested solidarity top-up benefit from EKAS if their income was below $€ 9,200$ per annum, that is almost twice as large as the poverty threshold and above the minimum wage $(€ 7,963)$. In comparison, in Germany, the income eligibility threshold for means-tested pensions was about $3 / 4$ of the 2013 poverty level of $€ 11,749$ - that is below the EKAS eligibility threshold in Greece-with no minimum limit on contributory pensions. As such, a minimum wage earner in Greece contributing for 15 years would have received a guaranteed pension similar to the pension received by a retiree who worked and contributed for 31 years and would thus have no incentive to

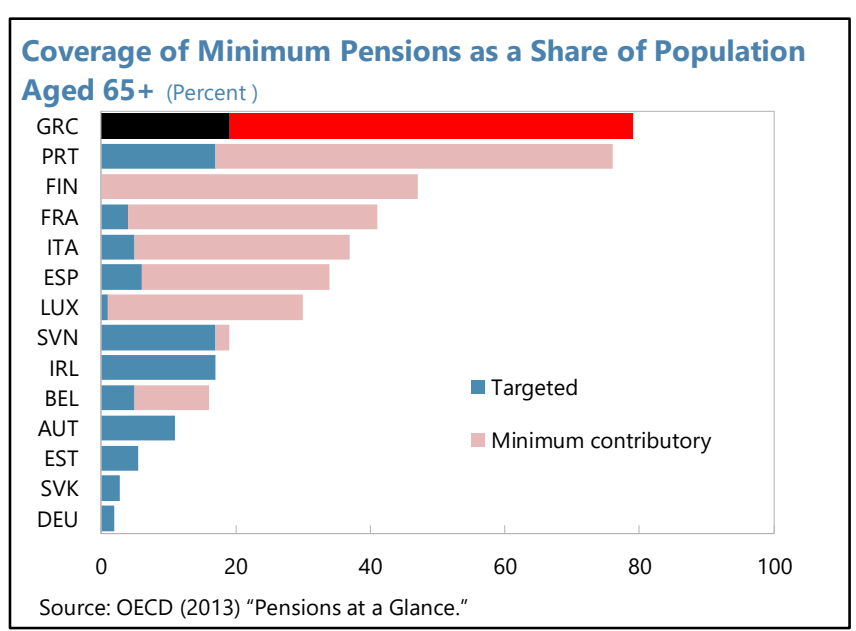

\footnotetext{
${ }^{10}$ In the euro area, minimum pension and safety net protection is in the range of 50-80 percent of the poverty threshold (World Bank, 2013a,b; MISSOC 2016 comparative tables on social protection).
} 
contribute beyond the minimum 15 years. Greece stood out in the euro area as the country with the highest ratio of the elderly receiving minimum pensions. ${ }^{11}$

12. As a result, retirement with few years of contributions remained prevalent. Despite the increase in the early and standard statutory retirement ages to 62 and 67 years, respectively, the average retirement age of old-age retirees fell to 59 years. This reflects the fact that vested rights were protected under all previous reforms by grandfathering those insured with accrued rights to retire (those fulfilling either the retirement age or years of contributions requirements). Consequently, the distribution of retirement applications in Greece at end-2015 remained skewed toward few years of formal work, with a spike at 15 years (14 percent of total applications) required to qualify for an oldage pension, and about half of retirement applications made by 26 years of contributions. Only about $1 / 4$ of applications were made after 35 years of contributions - the required contribution period in the past - and a small fraction were made after the post-2010 requirement of

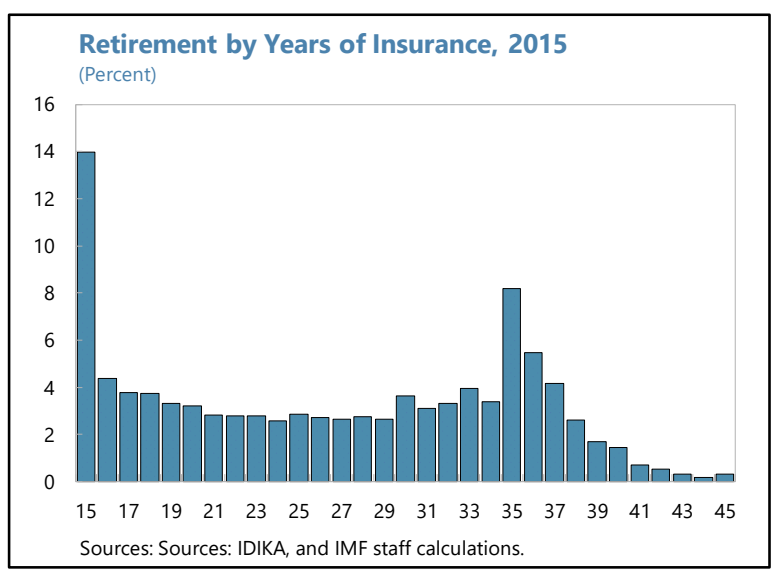
40 years.

\section{Incentives to contribute have been particularly weak for the self-employed. Even} after the 2010-12 reforms, the contributions of the self-employed continued to be based on assessed earnings (notional income based on number of years of experience) instead of on actual earnings. ${ }^{12}$ This meant that for the young self-employed with short experience history (even in lucrative professions), the base for calculating benefits was similar to the minimum wage, implying pension rights much below the minimum pensions at minimum required 15 years of insurance, and thus creating incentives to minimize contribution payments and histories. But also the more experienced and higher income professionals who cannot build up their pension rights based on their actual earnings can have stronger incentives to underreport income to avoid taxation or find it

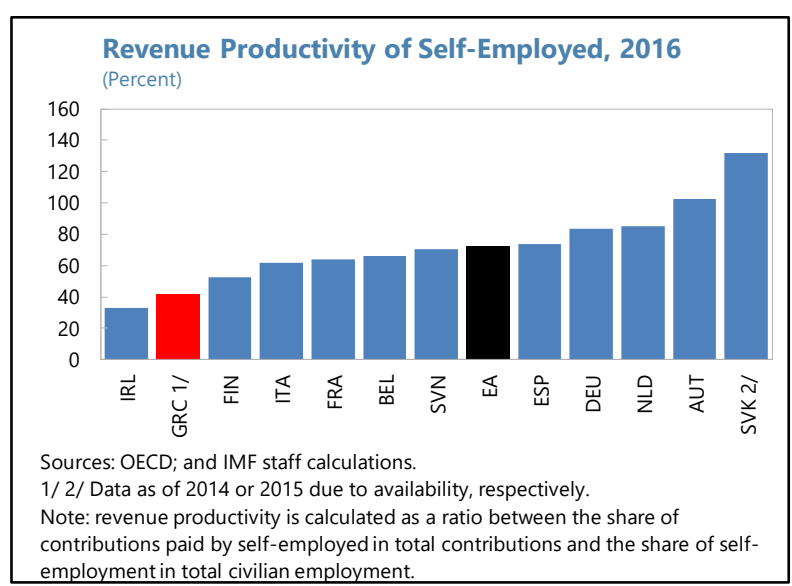

\footnotetext{
${ }^{11}$ Gruber and Wise (2004) and others show that financial incentives for continued work and early retirement options are the strongest determinants of labor force participation among elderly workers. Jiménez-Martín and Sánchez Martín (2007) and Jiménez-Martín (2014) find evidence that generous retirement protection increases early retirement probabilities and results in fewer working hours. Joubert (2015) has shown that more generous minimum pension guarantees lead to a significant reduction in labor force participation at older ages and transfer of workers towards informality or home production, especially for women.

12 The main fund for self-employed (OAEE) had 14 notional income classes, with $1 / 4$ of insured qualifying for the lowest notional income class ( $€ 763$ per month) and $2 / 3$ for the four lower income classes (up to $€ 1,213$ per month). The minimum notional income scales in other funds for self-employed (OGA, TSAY, TSMEDE, TAN-TEAD) are even lower, ranging from $€ 487$ to $€ 693$ per month.
} 
beneficial to operate in the shadow economy. ${ }^{13}$ As a result, and in addition to exemptions most notably provided to farmers and newly insured professionals, the share of social contributions paid by self-employed (16 percent) is less than half of the share of self-employed in the economy (35 percent of total employment), resulting in one of the lowest "revenue productivities" of selfemployed in the euro zone.

\section{REFORM OBJECTIVES AND RESULTS}

\section{A. The 2015-16 Pension Reforms}

14. In 2015-16, the authorities renewed the reform efforts, seeking to address the structural deficiencies in the pension system and reduce its medium-and long-term costs. The main structural changes aimed at, inter alia: (i) tightening early retirement rules; (ii) harmonizing the main pension benefit rules, including to address the CoS ruling; (iii) phasing out the solidarity grant EKAS; (iv) putting auxiliary, dividend, and lump-sum funds on more sustainable footing; (v) harmonizing contribution rules; and (vi) consolidating the main pension funds. The reforms also aimed to achieve fiscal savings of about $1 \frac{1}{2}$ percent of GDP by 2018 (IMF, 2017a,b) ${ }^{14}$.

\begin{tabular}{|c|c|c|c|c|}
\hline \multicolumn{5}{|c|}{$\begin{array}{l}\text { Estimated Fiscal Savings from the 2015-16 Pension Reforms } \\
\qquad \text { (Percent of GDP) }\end{array}$} \\
\hline & 2015 & 2016 & 2017 & 2018 \\
\hline TOTAL & 0.2 & 0.7 & 1.2 & 1.5 \\
\hline Benefits & 0.0 & 0.3 & 0.7 & 1.0 \\
\hline Tightening early retirement rules & 0.0 & 0.0 & 0.1 & 0.1 \\
\hline Phasing out social solidarity grant EKAS & & 0.0 & 0.3 & 0.4 \\
\hline Main pension benefit reform & & 0.0 & 0.1 & 0.2 \\
\hline Summplementary, lump-sum, and dividend fund reforms & & 0.2 & 0.2 & 0.2 \\
\hline Other (incl. wider eligibility for social pension, lower ceiling) & & 0.0 & 0.0 & 0.0 \\
\hline Contributions & 0.1 & 0.4 & 0.5 & 0.5 \\
\hline Raising health contributions for retirees & 0.1 & 0.3 & 0.3 & 0.3 \\
\hline Harmonizing contribution rules and base & & 0.0 & 0.0 & 0.0 \\
\hline Temporary increace by $1 / 0.5 \mathrm{pp}$ in supplementary contributions & & 0.1 & 0.2 & 0.2 \\
\hline
\end{tabular}

15. The reform overhauled early retirement rules. To contain the excessive grandfathering of retirement rights allowed under the previous reforms, the authorities required a gradual convergence by 2022 of all existing grandfathered retirement ages toward 67 years (or 62 years with 40 years of contributions). ${ }^{15}$ It also increased the benefit discount for each year of early retirement from 6 to 16 percent for those affected by the reform and abolished mandatory retirement of civil servants. However, the reform was not able to change the eligibility to retire at earlier ages for those who by 2015 had reached both the required retirement age and years of insurance (vested rights) and did not eliminate grandfathering on the basis of years of insurance, thus exempting a large number (up to $3 / 4$ ) of civil servants with a short period of service.

16. It also harmonized the main pension benefit rules. The reform introduced a single uniform benefit rule for both existing and new retirees in the spirit of the 2010 law, consisting of basic and contributory components. The basic pension component was increased from $€ 360$ to

\footnotetext{
${ }^{13}$ Artavanis et al. (2015) estimate, based on household credit microdata, that self-employed in Greece do not report about 45 percent of their income. They also find that tax evasion in Greece is concentrated among highly educated and high -income professions such as doctors, engineers, lawyers, accountants, educational service providers, and financial service agents. Tax evasion among self-employed in Greece does not only take the form of underreporting but also over expensing through "miscellaneous" expenses that sometimes can form up to half of their total costs.

14 The figures in the text table correspond to IMF Staff estimates at the time when reforms were legislated.

${ }^{15}$ Arduous and hazardous workers, disabled, survivors, and some vulnerable groups could still retire at earlier ages.
} 
$€ 384$ per month at 20 years of insurance (corresponding to the 2014 poverty level) ${ }^{16}$. To compensate for the increased cost, the new benefit formula for contributory pensions was based on lower marginal accrual rates (in the range of 0.77 to 2 percent, depending on years of insurance). For new retirees, the new benefit rule is applied without pro-rating over the previous more generous rules. For existing retirees, the main pensions were frozen at the end-2014 level (pre-dating the $2015 \mathrm{CoS}$ ruling) to maintain the savings achieved from the 2012 cuts. The freeze implies that in cases where the new benefit formula suggests a pension lower than the end-2014 level, the paid-out pension remains unchanged, and the resulting notional "negative difference" with the formula-implied level will be eroded only gradually through indexation. In other words, current pensioners would not suffer additional reductions in main pensions even if the new formula suggests otherwise but would also not see their nominal pensions increasing as long as the new formula-implied benefit remains below the end-2014 pension level (about 1.4 million current pensioners fall into this category). Any "positive differences"-i.e. where the formulaimplied pension payment would be higher than the end-2014 benefit level — were set to be eliminated over 5 years in equal steps starting from 2019.

\section{The reform transformed the system of basic, minimum guaranteed, and targeted} pensions. With a higher basic pension, the minimum guaranteed pension limits became redundant and were eliminated for all retirees across all funds, except those with work-related disabilities. ${ }^{17}$ Importantly, the authorities started to phase out the noncontributory solidarity grant EKAS (implying also abolition of associated non-pension benefits such as lower pharmaceutical copayments) by end-2019 that distorted incentives to retire and was not compatible with the contributory insurance-based system. However, they subsequently provided several fragmented forms of compensation to those beneficiaries who lost EKAS in 2016 and distributed a "bonus" for 2017 to retirees with pension benefit below $€ 850$ per month as the sole income criterion, which is the pre-reform limit for payments of EKAS, in effect neutralizing the impact of the reform in 2016-17.

\section{Principles of pensionable earnings and valorization were significantly revised. The} reforms retained the important principle of the 2010 law to relate pensions to life-time earnings, though, since the electronic records are predominantly available since 2002 , this objective will be achieved only gradually. Crucially, the valorization of pensionable earnings was changed from inflation to nominal wages, which, while increasing replacement rates and benefits in the long-run, is fairer, more equitable, and in line with best practices. In early 2017 the move from inflation to wage valorization was postponed until 2021.

19. Measures were taken to reduce the medium-term deficit of supplementary pensions. The authorities legislated selective cuts of supplementary pensions for pensioners with total (main plus supplementary) pension benefits above $€ 1,300$ per month, affecting about 200,000 current retirees and froze supplementary pensions as long as the funds remain in deficit. These cuts were calculated based on a unified 0.45 percent accrual rate applied on pensionable earnings

\footnotetext{
${ }^{16}$ The basic pension was renamed as national pension, and the benefit level of $€ 384$ per month is reduced by 2 percentage points for each year below 20 years of contributions. The minimum contribution for eligibility remained at 15 years at which point the basic pension reduces to $€ 345.6$ per month. The benefit level will be indexed to the general pension indexation rule, when the current freeze is lifted.

${ }^{17}$ In 2021 minimum guaranteed pension limits were reintroduced for writers, artists, and National Resistance veterans.
} 
up to end-2014; beyond that the NDC formulae as introduced with the 2012 reform applies. Below $€ 1,300$ monthly benefits, notional "positive" and "negative" differences against the new formula-implied benefits were created. However, since these measures were insufficient to close the deficit in supplementary funds (which amounted to about 0.4 percent of GDP at end-2015), the authorities also temporarily increased supplementary social security contribution rates by 1 percentage point until May 2019, when this increase will be phased out, and pledged to use the assets of the supplementary fund to cover remaining deficits. The increase in the contribution rates rolls back previous attempts to reduce it. It also generates additional pension entitlements, given that supplementary funds operate under a notional defined contribution (NDC) regime. ${ }^{18}$

\section{Benefit rules for several other pension components were streamlined and}

harmonized across categories. Accrual rates in dividend funds were reduced to 0.215 percent for all retirees with automatic adjustment mechanism to eliminate any annual deficits. Replacement rates were harmonized and reduced across all lump-sum funds to 60 percent with full earnings valorization for insurance years up to 2013 and NDC beyond that. Child and spouse bonuses provided through the pension system were abolished for new retirees, harmonizing the treatment with general family benefits. An age requirement of 55 years was introduced for the surviving spouse to be entitled to a permanent survivor pension; below that age, survivor pensions were limited to 3 years (nevertheless, 2 -year contribution subsidy was allowed within 5 years from the gathering of temporary survivor pension). Disability pensions were fully shielded from cuts with a requirement to introduce revised unified benefit rules. Any preretirement pensions were abolished for new retirees and recalibrated for existing retirees, multiple basic pensions were abolished, and spending ceilings were abolished for new retirees while temporarily lowered for pensions in payment until end-2018 (in expectation of recalibration of existing pensions).

\section{The reform sought to harmonize pension and health contribution rates as well as} contribution bases for the self-employed. Main pension contributions were harmonized at 20 percent for all employees (implying an increase for farmers by13 percentage points over five years), and health contribution rates for retirees were increased to 6 percent (from 4 percent in the main funds and 0 percent in the supplementary funds). Ceilings for monthly earnings to calculate contributions were increased slightly to $€ 5,860.8$ (10 times the minimum wage) and harmonized for all insured. Importantly, the reform transformed the social security contribution base for self-employed from notional to actual earnings, subject to a minimum income limit, ${ }^{19}$ and eliminated all third-party charges (nuisance charges) previously used to predominantly finance the deficits of pension funds for the self-employed, but also of other categories such as employees of ports and oil companies, municipal workers, policemen etc. However, the reform did not fully eliminate existing exemptions for vested interest groups (e.g. lawyers, doctors, engineers and other highly qualified self-employed), who still benefit from reduced rates and

\footnotetext{
${ }^{18}$ In the NDC scheme the higher contribution rate feeds into accumulated notional capital that in turn determines the pension benefit at retirement.

${ }^{19}$ This limit was applicable only to the self-employed and is equal to the minimum salary of an unmarried employee above 25 years of age, which at the time of reforms amounted to $€ 586$ per month.
} 
from a 30 percent discount on the minimum earnings limit (the latter also applies to farmers). ${ }^{20}$ The contributions base for self-employed was initially set lower compared to salaried workers net of social contributions (later changed to gross of social contributions for 2018 and 2019), and pension benefits for the self-employed accrue even if they do not stay current with their contribution obligations. ${ }^{21}$ Such exemptions for the self-employed are not common practice in other euro area countries, and risk perpetuating both the financial imbalances of the pension funds and the perception of lack of fairness of the system as a whole.

\section{Finally, an ambitious agenda was set for digitalization, transparency, and} administrative merger of funds. The Greek pension system stood out as one of the most inefficient in Europe with high administrative costs. To reduce these costs and create economies of scale, a single unified pension fund (EFKA) was created for all retirees with single management and administrative functions. All other funds (except non-pension activities of OGA and NAT as well as dividend funds for civil servants) and their existing governance and management arrangements were set to be abolished. Electronic records were set to be created for both new retirees - to facilitate the recalibration - and existing retirees - to minimize errors, speed up the processing of pensions, and eliminate the vast backlog of unpaid pension obligations.

\section{These measures, if fully implemented, would lower the pension expenditure toward} the European average in the long run. However, the pension system would remain costly, in particular during the transition period, distortive, and subject to legal uncertainties:

- Medium- run implications. Despite aiming to achieve savings of $1 \frac{1}{2}$ percent of GDP by 2018, the reform still left a significant pension system deficit (7-8 percent of GDP) over the medium-term, after the output gap closes, which is still far above the euro-area average. This will continue to consume resources from the general budget, preventing the government to reallocate spending to other priorities, such as public investment, targeted social welfare, and other essential public services such as health care.

- Long-run implications. The 2018 Ageing Report (EC, 2018) that incorporates the full scale of 2015-17 reforms projects the Greek pension expenditure to decline to 13 percent of GDP by 2040 and further to $11 \frac{1}{2}$ percent of GDP by 2060 (Box 2). While the introduction of the new (higher) national pension led to an increase in the benefit rate - the ratio of average pension benefits to average wages - by more than $1 \frac{1}{2}$ percentage points on average $\left(3 \frac{1}{2}\right.$ percentage points for a minimum wage earner) compared to the pre-reform regime, the overall impact of the reforms is expected to reduce steady-state replacement rates (average pensions relative to pensionable wages) by about 4.4 percentage points. These savings would

\footnotetext{
20 These categories are allowed to pay 14 percent for the first 2 years and 17 percent for the next 3 years, with the remaining amount up to harmonized 20 percent rate payable fully at the completion of 15 years of insurance or in annual payments of one fifth of the outstanding debt per year upon reaching a preset high income level of $€ 18,000$. The 30 percent discount is applied on the minimum income level on which contributions are paid, reducing it from $€ 586$ to $€ 410$ per month. The old - more generous rules - remain in force for seamen.

${ }^{21}$ This implies that the period when one is in arrears is counted as pensionable earnings up to a limit, and will add to pension rights, leading to higher pensions (at increasing marginal accrual rates). The contribution arrears are to be withheld from pensions at the time of retirement. The contribution arrears of self-employed(OAEE, ETAA, and OGA) reached 5.3 percent of GDP in 2015 .
} 
then be offset by moving from price to wage valorization that in the steady-state, and under staff long-term economic projections (see IMF, 2017b), can add 5-6 percentage points to gross replacement rates of an average earner around 33-36 years of full service immediately before retirement. ${ }^{22}$ The long-run savings therefore crucially depend on restrictions on eligibility and clean-up of other components of the pension system.

Nevertheless, , even if all reforms were fully implemented as captured in the 2018 Aging Report, in the long-run steady state Greek pension system would still require about 4 percent of GDP in state transfers and provide lifetime benefits that exceed lifetime contributions by about 1.5-1.7 times, falling short of sustainability (Fouejieu and others, 2021).

- Incentives to contribute. At the same time the combination of higher national pension and lower accrual rates imply much flatter pension benefit profile and a worsening of contribution-benefit links, with adverse implications for labor force participation. ${ }^{23}$ Moreover, the combined national and contributory benefit at 15 years of insurance still provides a generous minimum pension guarantee (estimated at around 115 percent of the poverty threshold, compared to a euro-area average of around 70 percent, as noted in EC-SPC $2015 a, b)$. This reinforces existing incentives to retire at short careers.

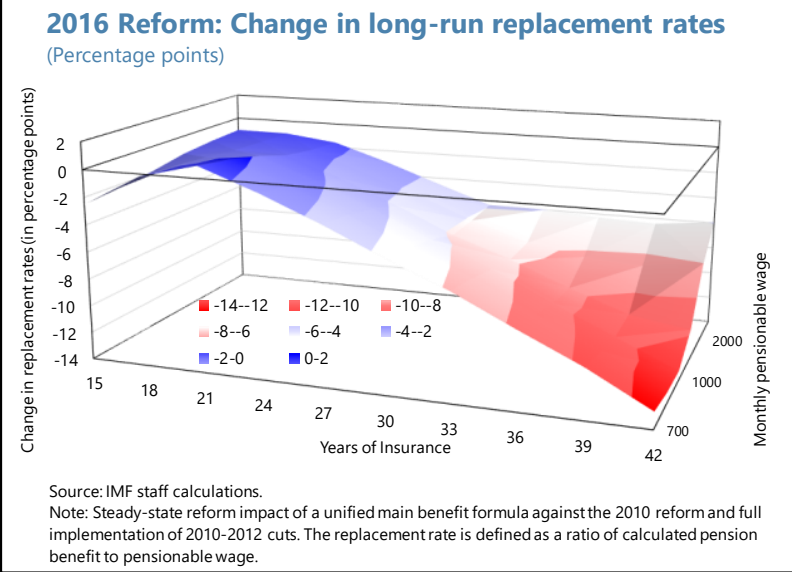
implementation of 2010-2012 cuts. The replacement rate is defined as a ratio of calculated pension benefit to pensionable wage.

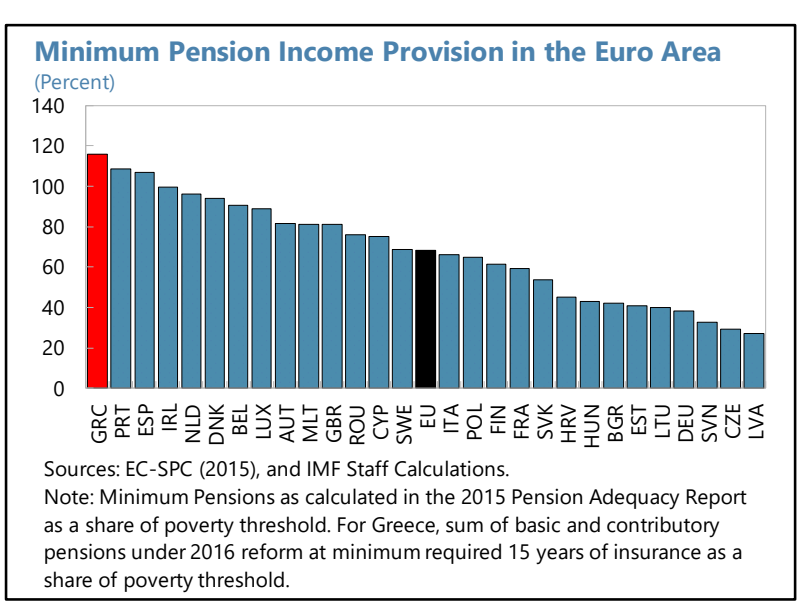

- Fairness. The fiscal adjustment delivered by the main pension recalibration and supplementary benefit reductions is largely borne by new generations of retirees with longer careers. In contrast, individuals with shorter careers (e.g. around 20 years) can see their future replacement rates and average pensions even increasing. Moreover, the main pensions of current retirees were protected through the pension freeze, exacerbating already large

\footnotetext{
22 Abolition of minimum pensions is assumed not to affect these results, since the 2010 law set the minimum threshold at 15 daily wages of an unskilled worker ( $€ 392.7$ per month according to the last collective labor agreement) that is less than the sum of basic and contributory pensions at 15 years of insurance (under wage indexation) and is therefore assumed to be non-binding at the steady state. Gross replacement rates for an average earner reported in OECD (2013) and OECD (2017) - after 2010 and 2015-16 reforms, respectively - are also similar in the order of 54 percent.

${ }^{23}$ With weaker links between earnings and benefits, contributions are perceived as distortive labor taxes that impinge on employment incentives, rather than deferred savings (IMF 2012; Disney et al., 2004). Progressive accrual rates that value additional years of work more than previous years are very rare in practice. In Greece the 2010 reform introduced such progressivity to "offset" already back then the high flat basic pension granted to everybody notwithstanding their income level.
} 
inter-generational imbalances. Finally, as noted above, specific interest groups continue to benefit from exemptions and special treatment and the system remains actuarially unfair.

- Risks. In 2015, the Council of State (CoS) ruled the 2012 cuts in pension benefits unconstitutional. While the number of pensioners eligible for retroactive compensation under the ruling was limited according to the initial decision, ongoing court procedures and new challenges for extending the eligibility and compensation period could still result in large retroactive payments. A recent $\mathrm{CoS}$ "pilot" trial was expected to clarify unresolved issues regarding retroactive payments (such as the number of beneficiaries and exact eligibility period) related to the 2015 decision. ${ }^{24}$ Following its issuance in July 2020, the government ordered retroactive payments covering an 11 -month period to all pensioners (private and public sector) amounting to almost 1 percent of GDP. ${ }^{25}$ These payments, however, exclude holiday bonuses and supplementary pensions with varying opinions as per whether the government order fully complies with the court's verdict. Therefore, new claims cannot be ruled out going forward. The 2016 reform was also subject to legal uncertainties, as it preserved the structure of the 2012 cuts, which had been ruled unconstitutional in 2015 , and added new progressive cuts on some of the same groups of retirees. A CoS ruling issued in October 2019 appears to have contained this risk. The court ruled in favor of the merger of social security funds into the new single entity (EFKA) and the recalculation of pension benefits foreseen in the 2016 reform. However, the ruling also requested adjustments to both contribution and pension benefit levels that will result in higher costs over the longer run. It also called for an adjustment of pension contributions for the self-employed (previously harmonized with private-sector employees' contributions).

\section{B. The 2017 Reforms}

\section{The 2017 reform package that aimed to rebalance the fiscal policy mix to support} growth and social inclusion was not implemented. The reform strategy consisted of prelegislating a package of fiscal measures, including further permanent pension reforms, which were scheduled to take effect from 2019 after the output gap was expected to have narrowed substantially. The implementation of the pre-legislated measures would have created fiscal space for more targeted social spending, investment, ALMPs, and tax cuts, while still respecting the ambitious medium-term primary surplus target of 3.5 percent of GDP. ${ }^{26}$ The relevant provisions were subsequently abolished in December 2018, a few days before their scheduled entry into effect.

\footnotetext{
${ }^{24}$ The concept of "pilot trials" was introduced in the Greek legal system in 2010. It means that the effects of the decision will apply not only to claimants but will have an across-the-board application. In this instance, the pilot trial approach was chosen as there are numerous similar appeals pending acros s various levels of the Greek judicial system.

25 The 11 -month period corresponds to the period between the issuance of the initial $2015 \mathrm{CoS}$ decision (in June 2015) and the time the 2016 reform came into effect (in May 2016). The court considered that the State failed to comply with its decision during this period.

${ }^{26}$ IMF (2018) country report provides details on the reform principles.
} 

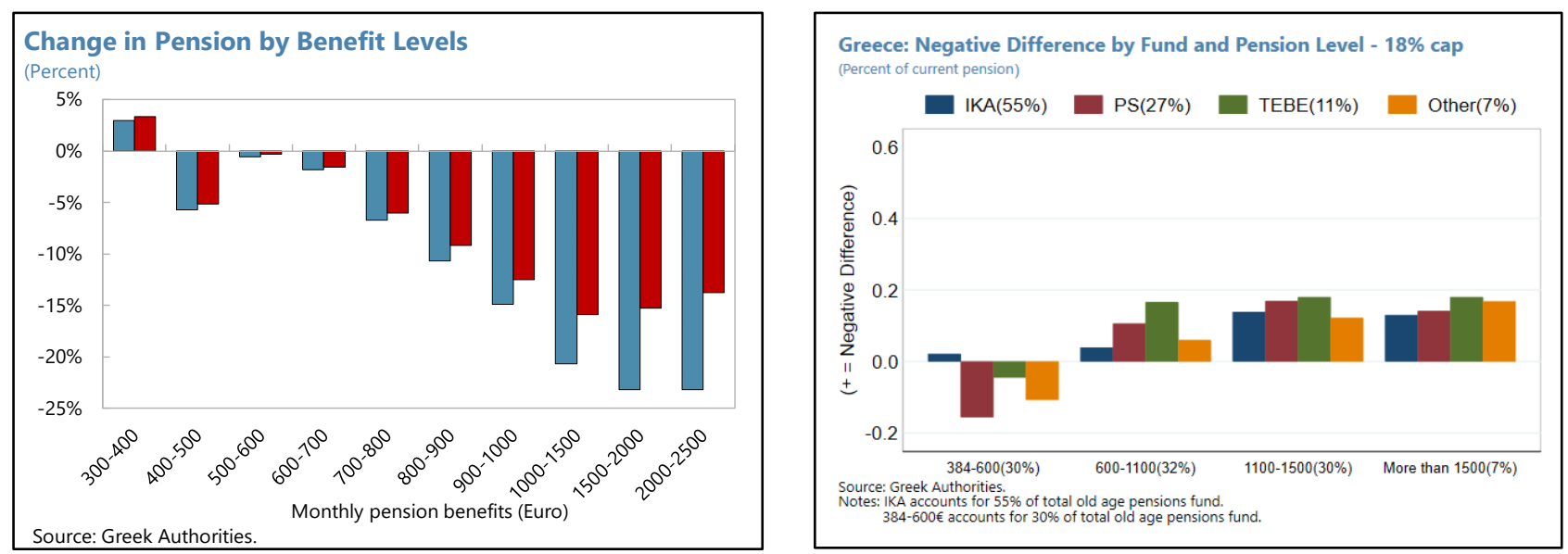

\section{The 2017 pension reform would have affected existing retirees, delivering net} savings of 1 percent of GDP. The reforms, legislated to take effect from January 1, 2019, would have extended the 2016 main and supplementary pension benefit rules to all existing retirees, directly recalibrating their current pensions without transitional arrangements (thus eliminating the aforementioned notional "negative" personal differences). Reductions either in main or supplementary pension benefits (separately, including family allowances) were capped at 18 percent. For main pensions, cuts would have affected about 1.4 million pensioners (about 70 percent of the pensioners in 2015), and the average decline for those with "negative" difference s would have been around 14 percent. The inflation indexation suspension for all pensions extended until end-2022 was retained.

\section{Extending the new pension benefit rules to existing retirees would have improved} the fairness of the pension system. As shown in the text chart, the unconditional recalibration of existing old-age pensions would result in larger cuts for high-income retirees with shorter years of contributions while slightly increasing pension benefits for lower-end pensioners with higher years of contributions. Also, the application of a new single benefit formula would lead to higher cuts to those retired under more generous former pension funds, improving intragenerational fairness in sharing the fiscal adjustment burden. However, the 18 percent cap on pension reductions lowered the re-distributional impact by limiting benefit reductions at the upper end of the distribution.
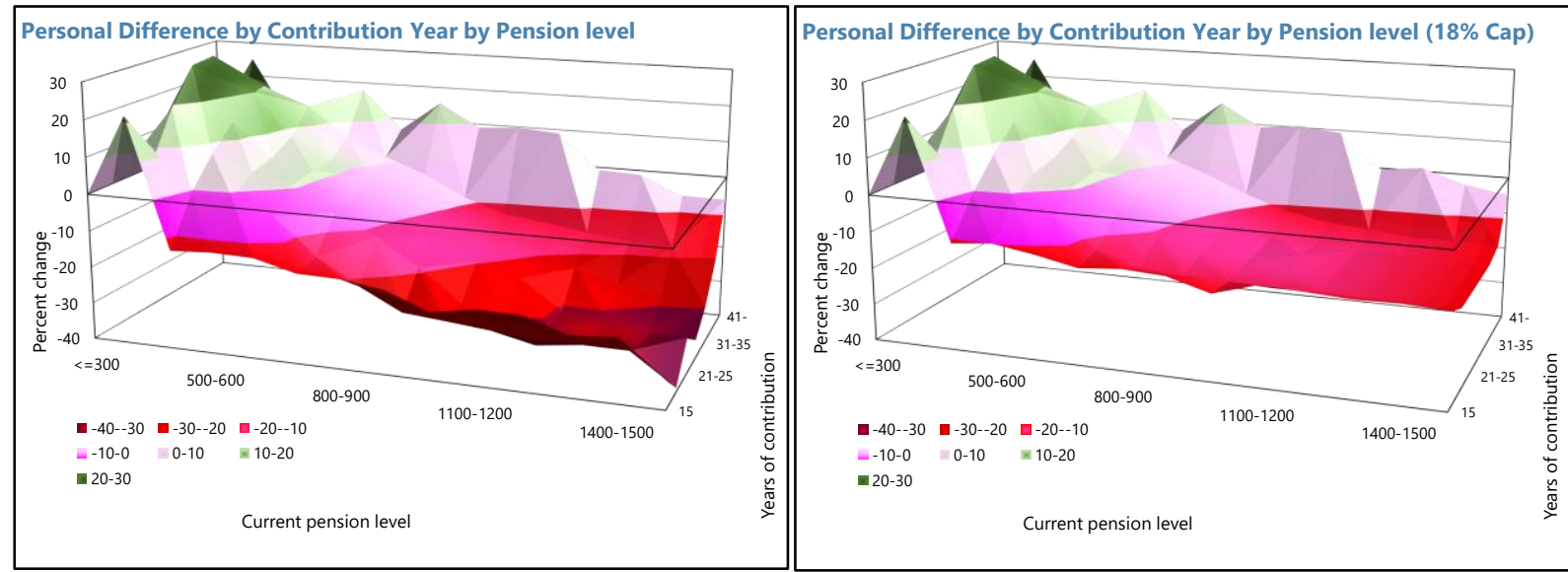
27. The reform would have been accompanied by further changes to the minimum pensions and family benefits. In line with the direct recalibration of pensions, the past generous family bonuses still granted to existing retirees would also have been eliminated, allowing harmonization of family benefit rules with new retirees. However, this reform was abolished before its entry into effect. At the same time, a minimum was introduced for survivors' pensions equivalent to the national pension of the main pension system at $€ 384$ at 20 years of insurance of the deceased with a floor of $€ 360$ at 15 years of insurance.

28. The pre-legislated pension cuts would have allowed faster convergence to the lower long-run level of pension expenditure and fairer treatment of generations. The paths with and without the pre-legislated pension recalibration would converge eventually (with the 4-year indexation freeze in both cases), meaning that the 2017 reform would have had little impact on long-run pension expenditure. However, the reform would have eliminated the negative differences upfront, thus freeing up fiscal space cumulating to about 10 percent of GDP over 20 years during the transition period and ultimately enhancing intergenerational fairness of reforms through more equitable burden sharing. This additional fiscal space would have financed the rebalancing of the fiscal mix toward growth and social inclusion, helping finance direct tax reductions and more targeted social spending while honoring the ambitious medium-term primary balance targets.

\section{Post-program developments}

29. In addition to the cancellation of the 2017 reform, program exit was accompanied by rollbacks of several other pension-related reforms. In 2018, pension contributions were reduced (by ca $1 / 3$ ) to 13.33 percent for the self-employed and professionals, and 12 percent for farmers, in some cases retroactively for 2017 . In addition, a temporary 50 percent subsidy on employers' contributions to pensions for the youth was introduced. Earlier reforms to survivors' pensions were also reversed in 2019 by reinstating the previous benefit level ( 70 percent of the deceased's pension instead of 50 percent) and relaxing age-related eligibility criteria. An "Easter" pension bonus (13 ${ }^{\text {th }}$ month payment) was reintroduced as a permanent measure in May 2019 for about 2.5 million pensioners. The measure (which had been abolished in 2012) cost approximately $€ 900$ million or 0.5 percent of GDP annually.

\section{A new pension law adjusted elements of the 2016 reform to address a recent $\mathrm{CoS}$} ruling. A CoS decision issued in October 2019 called for adjustments to the 2016 law.

Even though the impact of the ruling was smaller than originally anticipated, the court called for adjustments in three important areas: (i) to increase spending on supplementary pensions (as 2016 cuts were deemed unconstitutional); (ii) to increase replacement rates for main pensions for retirees with longer contributory periods (that were deemed too low); and, (iii) to adjust social security contributions for the self-employed (previously harmonized with

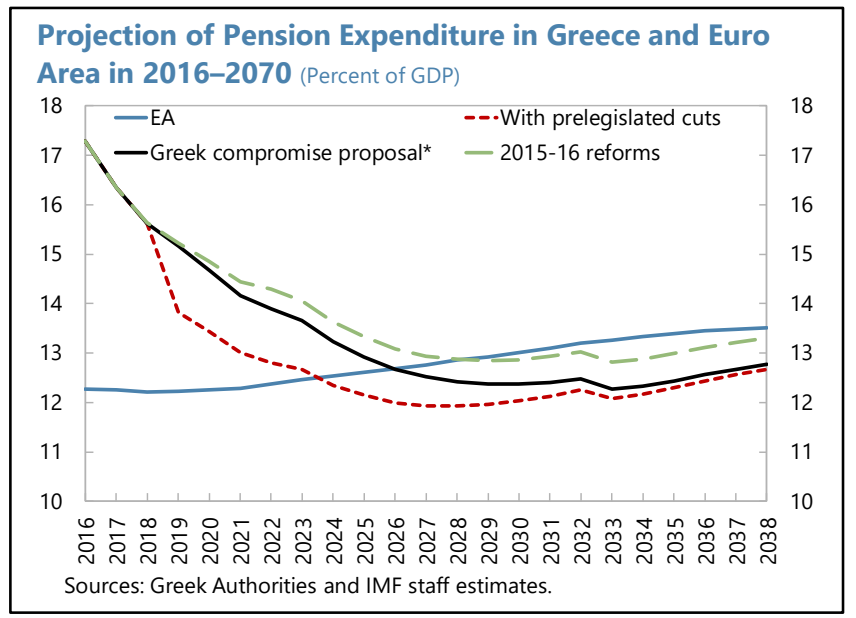


private-sector employees' contributions). The new pension law adopted in February 2020 addressed these points by applying higher accrual rates for workers with longer contributory periods, by restoring the level of supplementary pensions to the level mandated by the court and by modifying the social security contribution system for the self-employed, effectively delinking it from income and offering a menu of contribution and benefit scales instead (thus, reintroducing fragmentation into the system). The Easter bonus which had been restored in the previous year was abolished, in order to partially finance the higher main and supplementary pensions resulting from this ruling. The annual cost of the court ruling, initially estimated around 0.2 percent of GDP, will rise gradually over time, hitting 0.5 percent of GDP in the late $2040 \mathrm{~s}$ and eventually reaching 0.7 percent of GDP in 2070 . The text chart presents updated pension expenditure projections including the effect of the 2020 pension law.

31. Medium and long-term costs may increase further in the future. The 2021 Ageing Report (EC, 2021) that incorporates also the post-program developments projects both annual pension spending as well as contributions to increase by about 1 percent of GDP in the long run (vis-à-vis the 2018 Ageing Report projections), leaving the annual deficit on the order of 4 percent of GDP. Transitional costs will increase in the event that the government proceeds with its plans to introduce a three-pillar system, transforming the supplementary pension funds for the newly insured from a pay-as-you-go into a fully-funded scheme and introducing private insurance. The government has also committed to a gradual reduction in social security contributions by 5 percentage points during $2020-2023 .{ }^{27}$ Furthermore, while legal risks have decreased, they have not been entirely eliminated as the pilot trial decision on the 2015 reform is still pending and new challenges continuously emerge.

\footnotetext{
${ }^{27}$ Out of the announced 5 percentage point reduction in social security contributions, 0.9 percentage points has been in effect as of June 2020, and additional 3 percentage point reduction was legislated for 2021 and announced for 2022 . These reductions thus far do not concern pension contributions.
} 
Box 2. Long-Term Pension Spending Projections

The 2015-2017 pension reforms have a potential to significantly improve the affordability of the Greek pension system. The gross repla cement rates of oldage main pensions, the largest component of the pension system, remain broadly comparable to those under the 2010 reform, as the reductions in a ccrual rates a re offset by a shift from a price to wage valorization (see section III.A.). The medium-term and long-term sa vings compared to 2010 reform depend crucia lly on the recalibration of existing pensions (subsequently cancelled), restricting the pathways to early retirement and linking the retirement age to life expectancy, and streamlining the several excesses throughout the system. If fully implemented, this constitutes an impressive effort to bring Greece's pension spending in line with the rest of the Europe.

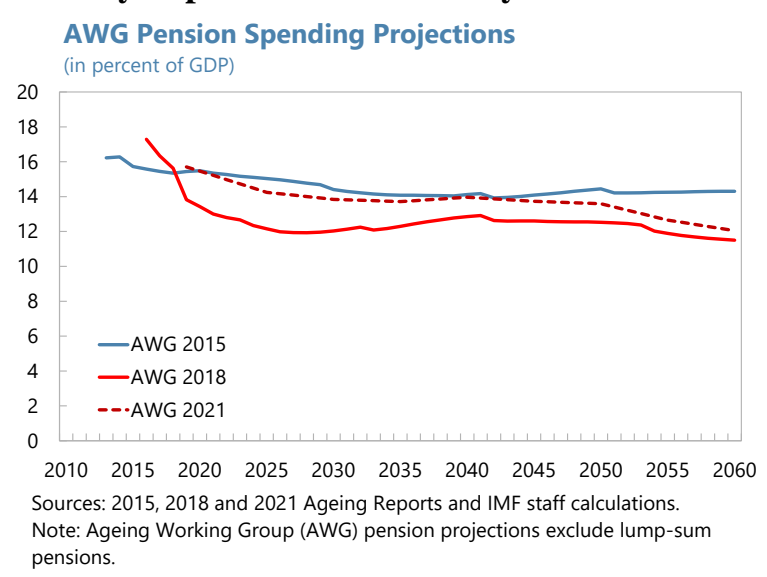

Implementation of 2015-17 reforms still carries several risks, highlighting the importance not to deviate from the set reform path. The implementation risks predominantly concern the following a spects:

- Reversals: abolishing pre-legisla ted recalibration of pensions (2017 reform), non-implementation of harmonization of contribution rules, and increased a ccrual ra tes will increa se the expected spending profile (not bound by benefit ceilings) and limit options for growth-enhancing and socially inclusive rebalancing of fiscal policy mix.

- Nationalpension: the pension benefits, including the national pension, a re indexed to inflation and last year's real GDP growth in equal proportions though cannot exceed the ra te of inflation. As a result, in longterm projections the national pension as a ratio to GDP would be gra dually deflated, leading to a bout $1 \frac{1 / 2}{2}$ percent of GDP in savings until2060. A more prudent assumption as upheld in a ctuarial projections of some other countries in similar situa tions would be to base long-term projections of national pensions to wage indexation.

- Labor market exitage: improvement in the labor market would allow the pension spending to decline by close to 5 percent of GDP in the long run, supported by linking the retirement age to life expectancy. With this the la bor market exit a ge is projected to increase substantially from 62 in 2017 (EC, 2018) to about 68 years (EC, 2018;2021). This is well above the projections for Germany (65.5) or the euro a rea (66), moving Greece from one of the worst to one of the best performers. Similar increases a re reflected in the a verage contributory periods. For such fundamental behavioral change to materialize, further structural reforms to strengthen la bor and product market incentives a re likely needed. Current design of the pension system still embeds powerful incentives to retire with 15-20 years of contributions and, unlike the retirement age, minimum years of contributions to qualify for a full pension are not linked to life expectancy, lea ving an early pathway out of labor market.

- Social benefits to retirees: since the gra dual a bolition of EKAS was legisla ted in mid-2016 the authorities have provided various fragmented social support that initially specifically ta rgeted retirees while later rea ching wider ca tegories. Such track-record of discretionary interventions call for caution in both pension spending a well a in setting primary balance targets.

- Other age-related spending: similarly, to pensions, a lso health and educational spending a re affected by population ageing and on net a re likely to a dd in excess of $1 / 2$ percent of GDP to public sector spending needs. Further, during 2010-15, health spending in Greece was compressed to one of the lowest levels in the Eurozone that is not sustainable (IMF, 2018).

- Legal risks: The legal risks from freezing the existing pensions at end-2014 level to predate the $2015 \mathrm{CoS}$ ruling a ppear to have decreased. In 2020, the government paid 1.4 billion euros in retroactive payments to public and private sector pensioners. A pilot trial expected to clarify further unresolved issues took place in January 2021, but its outcome is not yet known. 


\section{Conclusions And Policy Recommendations}

32. The Greek pension system has been complex and unaffordable, and earlier efforts to reform it have faltered. Generous benefits, nontransparent contribution rules, favorable treatment of special groups, and favorable early retirement options resulted in an unaffordable pension system. After two major attempts to reform the system and bring down medium-and long-term costs, pension spending in Greece at end-2015 remained the highest in the euro-area, requiring state transfers that are several times larger than the euro-area average. The prolonged economic downturn exacerbated the pension system's imbalance, although the key driver remained the structure of the system, based on overly generous benefits and a narrow contribution base.

\section{The 2015-2016 reform has many desirable features, though the overall pension} system remained costly. Overall, given the initial conditions the reforms legislated between 2015 and 2017 constitute an impressive effort by any standards. If fully implemented, the reform will consolidate the pension system's institutional structures and largely harmonize benefit and contribution rules. However, the system deficit over the medium term remains an outlier compared to euro-area peers, and even in the long run retirees would receive lifetime benefits that exceed their lifetime contributions about 1.5-1.7 times. Contribution-benefit links remain weak, limiting incentives to participate in the labor force, and the system is unfair with regard to the treatment of current and future retirees, as well as special interest groups.

\section{Lingering legal risks and rollbacks amid reform fatigue give rise to significant} implementation risks. While these reforms have the potential to considerably improve the affordability of the Greek pension system in the long run, several structural measures have been reversed and the projections remain subject to implementation risks (see Box 2). More prudent assumptions underlying the pension projections are called for, remaining pension system parameters should be clearly defined (e.g. disability pensions, contributory welfare benefits), while political ownership and legal uncertainties should be decisively resolved. Reform design that would appeal on shared principles of equity and fairer burden sharing could foster greater acceptability and durability of reforms.

\section{The 2017 reforms were a crucial step towards medium-term affordability and} creating space for growth-enhancing fiscal rebalancing. Immediate recalibration of existing pensions would deliver the needed savings to allow for growth-enhancing measures beyond achieving the primary balance targets. It would also improve inter- and intra-generational fairness by achieving more equitable burden-sharing across generations and imposing larger cuts for high-income retirees at shorter years of contributions while slightly increasing pension benefits for lower-end pensioners with higher years of contributions. The permanent nonimplementation of the 2017 reform is thus a lost opportunity.

36. Striving for efficiency gains, reducing administrative costs, and enhancing transparency should remain high on the reform agenda. NGEU funds provide an ideal opportunity to upgrade the digital infrastructure of pension funds. Completion of electronic records should be expediated for efficient recalibration of pensions and clearance of the stock of unpaid pensions to allow for realistic account of all obligations. Conflicting legislation should be 
abolished to allow full clarity on reform principles (e.g. calculating pension benefits only for periods during which contributions are actually paid).

37. In the medium term, the authorities should consider additional reforms to improve sustainability and incentives for longer contributions. To improve the system's fairness and efficiency, contribution-benefit links and resulting incentives to work and contribute can be further strengthened over the medium to long run and the level of national pension could be reviewed in light of international trends. Preferential treatments in terms of social contribution exemptions can be eliminated and contributions base for self-employed modernized to reflect actual earnings to strengthen fairness and sustainability. More equitable burden sharing across generations should be pursued that would create space for growth-enhancing fiscal rebalancing. Lowering the tax wedge as fiscal space allows would help strengthen work and contribution incentives. 


\section{References}

Andrews, D., Sanchez, A.C. and A. Johansson (2011), "Towards a Better Understanding of the Informal Economy," OECD Economics Department Working Papers No. 873.

Artavanis, N.T., Morse, A. and M. Tsoutsoura (2015), "Measuring Income Tax Evasion using Bank Credit: Evidence from Greece”, Chicago Booth Research Paper No. 12-25; Fama-Miller Working Paper.

Bundesversicherungsamt (2014), “Bericht der Bundesversicherungsanstalt fuer Angestellte.”

Disney R., Boeri T. and T. Jappelli (2004), "Are Contributions to Public Pension Programmes a Tax on Employment?” Economic Policy, Vol. 19, No. 39, pp. 267-311.

Duval, R. (2003), "The retirement effects of old-age pension and early retirement schemes in OECD countries," OECD Economics Department Working Papers, No. 370, OECD Publishing.

EC (2009), "2009 Ageing Report: Economic and budgetary projections for the EU-27 Member States (2008-2060)", European Economy 2|2009.

EC (2012), "The 2012 Ageing Report: Economic and budgetary projections for the EU27 Member States (2010-2060)”, European Economy 2|2012.

EC (2015), “The 2015 Ageing Report: Economic and budgetary projections for the EU27 Member States (2013-2060)".

EC (2018), "The 2018 Ageing Report: Economic and budgetary projections for the EU Member States (2016-2070)", European Economy, Institutional Paper 079.

EC (2021), "The 2021 Ageing Report: Economic and budgetary projections for the EU Member States (2019-2070)", European Economy, Institutional Paper 148.

EC-SPC (2015a), “The 2015 Pension Adequacy Report: current and future income adequacy in old age in the EU", Vol. I.

EC-SPC (2015b), “The 2015 Pension Adequacy Report: current and future income adequacy in old age in the EU. Country Profiles", Vol. II.

Fouejieu, A., Kangur, A., Martinez, S.R. and M. Soto, 202 1, "Pension Reforms in Europe: How Far Have We Come and Gone?” IMF Departmental Paper (forthcoming).

Gruber, J. and D.A. Wise (2004), "Social Security Programs and Retirement around the World: Micro-Estimation", NBER, The University of Chicago Press.

IDIKA (2015), "Monthly Representation of Pension and Welfare Benefits", Helios Report, October 2015IMF.

IMF (2011), "The Challenge of Public Pension Reform in Advanced and Emerging Economies", IMF Policy Papers. 
IMF (2012), "Fiscal Policy and Employment in Advanced and Emerging Economies", IMF Policy Papers.

IMF (2017a), "Greece. Request for Stand-by Arrangement—Press Release; Staff Report; and Statement by the Executive Director for Greece,” IMF Country Report No. 17/229.

IMF (2017b), "Reforming the Greek Pension System”, Greece: Selected Issues, IMF Country Report No. 17/41.

IMF (2018), "Greece. 2018 Article IV Consultation and Proposal for Post-Program Monitoring-Press Release; Staff Report; and Statement by the Executive Director for Greece," IMF Country Report No. 18/248.

Jiménez-Martín, S. (2014), “The incentive effects of minimum pensions," IZA World of Labor, Working Paper 2014:84.

Jiménez-Martín, S. and A.R. Sánchez Martín (2007), “An Evaluation of the Life Cycle Effects of Minimum Pensions on Retirement Behavior," Journal of Applied Econometrics, Vol. 22, pp. 923-950.

Joubert, C. (2015), "Pension design with a large informal labor market: evidence from Chile," International Economic Review, Vol. 56, No. 2, pp. 673-694.

OECD (2004), "Informal Employment and Promoting the Transition to a Salaried Economy," in OECD Employment Outlook.

OECD (2007), "Pensions: A comprehensive reform is urgently required", in OECD Economic Surveys: Greece 2007, OECD Publishing. http://dx.doi.org/10.1787/eco_surveys-grc-2007-5-en

OECD (2011), Pensions at a Glance 2011: Retirement-income Systems in OECD and G20 Countries, OECD Publishing. http://dx.doi.org/10.1787/pension_glance-2011-en

OECD (2013), "Pensions at a Glance 2013: OECD and G20 Indicators", OECD Publishing. http://dx.doi.org/10.1787/pension_glance-2013-en

OECD (2017), "Pensions at a Glance 2017: OECD and G20 Indicators", OECD Publishing. http://dx.doi.org/10.1787/pension_glance-2017-en

Queisser, M. and E. Whitehouse (2006), "Neutral or Fair? Actuarial Concepts and PensionSystem Design”, OECD Social, Employment and Migration Working Papers, No. 40, OECD Publishing.

Razafimahefa, I. (2017), "Addressing the Burden of Tax and Social Security Debt," IMF Country Report No. 17/41.

World Bank (2013a), "Review of Key Design Parameters and Legislation for Social Assistance Programs in Latvia," in Scientific Research: Latvia: "Who Is Unemployed, Inactive or Needy? Assessing Post Crisis Policy Options." 
World Bank (2013b), "Analysis of the Incentive Structure Created by the Tax and Benefit System," in Scientific Research: Latvia: "Who Is Unemployed, Inactive or Needy? Assessing Post Crisis Policy Options." 